\title{
Perspectives on Risk Perceptions
}

\author{
Gerald A. Cole ${ }^{1}$ and Stephen B. Withey ${ }^{2}$
}

Received January 13, 1981

\begin{abstract}
Drawing on the literature from the fields of cognitive and social psychology, sociology, and political science, we discuss perceptions of risks and benefits, the impact of perceptions and personal preferences on choice and behavior, the question of "socially acceptable" thresholds of risk, and the analytic and descriptive means by which such thresholds might be identified. We hypothesize that existing psychometric methods may be adapted for the scaling of perceived benefit. We review factors hampering the application of formal methodologies in the resolution of controversial public debates, and express doubt about the identification of a socially acceptable threshold of risk. We argue that the emphasis of research in this field should be shifted toward explicating the use of risk and benefit perceptions in the process of personal decision-making. Finally, we suggest several social science research approaches that may be used to address these issues.
\end{abstract}

KEY WORDS: risk perceptions; benefit perceptions; acceptable risk; decision processes.

\section{INTRODUCTION}

The discussion which follows is, primarily, a literature review, but one that is written from a particular perspective. As professional researchers, we have encountered the question of risk perceptions in a variety of contexts which, in the case of one of the authors, dates back more than 25 years. $^{(1-3)} \mathrm{We}$ also have tended to concern ourselves with topical questions that affect the population as a whole and with the social processes that are associated with them. ${ }^{(4-6)}$ As a result, this literature review will attempt to go beyond the research that usually is reported in relation to the perceptions of technological risk and to draw linkages between a number of recent research activities in psychology, sociology, and political science. In doing so, we hope to indicate

\footnotetext{
'Institute for Public Policy Studies, The University of Michigan, Ann Arbor, Michigan 48109

${ }^{2}$ Survey Research Center, Institute for Social Research, The University of Michigan, Ann Arbor, Michigan 48109
}

the possibilities for future research which might both broaden our understanding of risk perceptions and highlight their impact on personal preferences and the potential for social mobilization.

A growing body of research has been performed on perceptions of risks from technologies. Among other things, this research has demonstrated that "perceived risk" is a multidimensional concept and that only one of those dimensions corresponds, roughly, with a formal definition of risk in the same sense of deaths per annum. Though much less work has been done on the question of "perceived benefit," we hypothesize, on the basis of the reported results and in light of our previous work in other areas, that "perceived benefit" is also a multidimensional concept and that it can be scaled in a manner similar to that now used to assess perceived risks. We sense that new research efforts along these lines will be highly productive.

Our reading of the literature leads us to suggest that the focus of research in this field should be shifted toward an explication of the use of risk and 
benefit perceptions in the process of personal decision-making. At the present time, it is assumed that perceived risks weigh heavily in the decision; for example, to oppose the implementation of a new technology. The actual weight accorded to this aspect of the decision problem is uncertain, however.

In light of the complexities of social decisionmaking processes, and in view of the absence of data indicating the weights accorded to perceived risk in personal decision processes, we feel that it would be premature to attempt a specification of thresholds of "socially acceptable" risk. The results of formal, analytic methodologies are likely to be challenged by members of the lay public, or by socially and politically active groups seeking to represent the public's interests. Furthermore, the descriptive social sciences have not generated a body of data that could be used to justify any specific threshold. Social decisions are rarely made with respect to risk, per se. Rather, they evolve in relation to a proposed activity that entails risks, benefits, and a variety of less tangible considerations. The social risk may be balanced legitimately against these other considerations and one cannot say at the present time how this is done, either at the personal or at the social levels.

In the following section we review the recent work on risk perceptions, touching on the familiar topics of heuristics and biases and the multidimensional character of "perceived risk." We will discuss as well the possibility of developing measures of perceived benefit. Section 3. discusses the topic of "socially acceptable" risk and the factors which may affect the public's reaction to a particular technological program. And finally, section 4 . reviews briefly the literature concerning choice and decision-making in the face of risk and uncertainty. We focus on a few of the recently developed theoretical models which might be employed in future research on the topic of perceived technological risks.

\section{INDIVIDUAL PERCEPTIONS OF RISKS AND BENEFITS}

Perceived risk is considered formally to be a function of one's subjective probability estimates and is represented as the set of bets about uncertain outcomes that the decision-maker is willing to accept in attempting to make a specific choice. The criteria for validity for subjective probability estimates are rooted solely in the axioms of decision theory. Thus, different decision-makers can subscribe to different subjective probability estimates for the same set of events, and these subjective estimates need not, necessarily, conform with objectively derived probability estimates. Consequently, valid subjective probabilities that are "off the mark" will lead to perfectly defensible, though suboptimal, choices. In reference to policy choices associated with the risk of technologies, Slovic and his associates have commented that people "respond to the hazards they perceive. If their perceptions are faulty, efforts at public and environmental protection are likely to be misdirected."(7) This comment touches upon two interrelated points. First, one may speculate on the extent to which the risk perceptions of the lay public are calibrated with the "objective" estimates of risk that are being provided by technologists and professional risk analysts. The issue will be discussed in the section that follows. The second question concerns the weight assigned to risk perceptions, however well or poorly calibrated they may be, by members of the lay public when choosing between alternative courses of action that involve some element of risk. This question will be addressed in section 4 . of this paper.

\subsection{Calibration with Low-Probability, High-Consequence Events}

Researchers have developed a variety of experimental techniques to investigate the facility with which subjects conceptualize uncertainty as a probability distribution and the degree to which these subjective probabilities reflect objective evidence. In a review of studies concerned with "calibration" of such probability estimates, Lichtenstein and her associates conclude that most subjects fail to discriminate adequately among different levels of uncertainty and that the most common form of error is "overconfidence." ${ }^{(8)}$ Subjectively derived probability distributions tend to be too tightly grouped around the outcome perceived as most likely, and this point estimate is all-too-frequently wide of the mark. Related experiments have sought to determine whether and to what extent training, intelligence, and substantive expertise affect these judgments. The results appear to be inconclusive and frequently contradictory, though there is some evidence to suggest that training in the use of an elicitation procedure im- 
proves calibration $^{(8)}$ and that experts (e.g., professional weather forecasters) tend to be better calibrated than laymen..$^{(9-11)}$

Of particular concern for policy making purposes is the potential inaccuracy of judgments relating to low-probability, high-consequence events. Slovic and his colleagues have studied this question through a set of experiments in which subjects were asked to discriminate among various causes of death, the objective probabilities of which varied from about $1 \times$ $10^{-8}$ for botulism to about $8.5 \times 10^{-3}$ for heart disease. ${ }^{(12,13)}$ They found that:

(a) our subjects had a consistent subjective scale of relative infrequency for causes of death;

(b) this subjective scale often deviated from the true scale;

(c) the subjects could consistently identify which of the paired events was a more frequent cause of death only when the true ratio of greater to lesser frequency was greater than $2: 1$. At true ratios of $2: 1$ or below, discrimination was poor. ${ }^{(12)}$

Commenting on similar evidence, Slovic and his associates concluded that "in general, rare causes of death were overestimated and common causes of death were underestimated."(7)

\subsection{Heuristics and Biases}

Tversky and Kahneman, in reviewing the results of several experiments conducted by themselves and by others, have argued that systematic biases in the subjective assessment of probabilities can be traced to a "limited number of heuristic principles which reduce the complex tasks of assessing probabilities and predicting values to simpler judgmental operations." (14) They introduce three such heuristic principles labelled "representativeness," "availability," and "anchoring and adjustment" to account for the inconsistent and anomalous judgments they report.

The "representativeness" heuristic can lead to biased judgments through an over-reliance upon assessments of similarity between profiles that characterize the alternative outcomes and the schematic representations of examples that are presented (or stored in memory) as background information relevant to the task at hand. The evidence suggests that pattern matching dominates the judgmental process and that other, relevant considerations, such as the validity of the information presented, the prior probabilities, or the sample size, are discounted disproportionately.

In light of the weight that is accorded to pattern matching efforts during the derivation of probability estimates, one is led to speculate on the means by which relevant patterns or "schemata"(15) are mentally stored, recalled, and/or reconstructed: the "availability" of a representative pattern may substantially affect judgments of the probability of occurrence of events or outcomes that could be likened to that pattern. The availability of suitable schemata could be affected by the size of the class of instances which can be represented by that pattern, or by the emotional saliency of selected instances. For situations in which a suitable pattern is not readily recalled, the judgment of probability could be affected by the effectiveness of the search set used in making an infrequent or unfamiliar memory scan, or by the "imaginability" of an occurrence similar to the one implied by the pending judgment.

Error can be introduced as well through the inferential calculus by which an individual derives an explicit estimate of probability. Tversky and Kahneman ${ }^{(14)}$ note that subjects tend to derive their final estimates in relation to some initial value which is then adjusted in accordance with information relevant to the specific problem under consideration. These adjustments, however, tend to be insufficient, leading to final estimates that are biased toward the initial value that served as the "anchor" point.

Slovic, Fischhoff, Lichtenstein, and others have experimented with several psychometric techniques for the elicitation of individual perceptions of risk from a variety of technologies. Methods of obtaining individual estimates of "acceptable risk" and "gross benefits" have been tested as well. ${ }^{(7,16)}$ A principal concern of these experiments was to identify the factors that affect perceptions of risk from technologies. Risk estimates obtained from a small group of "experts" were highly correlated with statistical data describing annual fatalities, thereby indicating that, among experts, perceptions of risk were a function of the available statistical evidence and little else. Similar comparisons obtained for small samples of lay people, however, showed modest correlations at best, leading to the conclusion that perceptions of risk among lay people were based on other considerations. In light of Tversky and Kahneman's discussion of heuristics, one might speculate that an individual's 
perceptions of risk were a function of the qualitative characteristics that a subject was willing to attribute to a technology.

\subsection{Qualitative Risk and Benefit Perception: Attribute Profiles}

Slovic and his colleagues have explored this hypothesis by asking their subjects to generate risk profiles of selected technologies and activities using as attributional characteristics the dimensions of risk that have been suggested by Lowrance ${ }^{(17)}$ and others. The results of these experiments demonstrate that subjects can generate rather detailed "risk profiles" for technologies and hazards. Furthermore, through the use of multivariate statistical techniques (factor analysis) these profiles can be summarized within as few as three orthogonal dimensions. ${ }^{(7)}$ These three dimensions and their component attributes are summarized in Table I. Two of these three factors, whose components suggested the labels "Dread" and "Number of People Exposed" correlate well with the measure of perceived risk; the "Dread" factor in particular could explain a substantial portion of the variance in the measure [see Table IX, in ref (7) and also ref (16)]. These findings support the hypothesis that, among lay people at least, perceptions of risk from technologies are substantially affected by qualitative considerations that extend well beyond the more rigid, statistical definition of the concept.

The representativeness heuristic appears to play a particularly important role in shaping perceptions of risk from technologies. Whereas the "Exposure" factor was correlated with the indicator of perceived risk, the "Dread" factor appeared to be the primary determinant of perceived risk in these experiments. On the basis of this evidence, one suspects that perceptions of risk among lay people are strongly influenced by the individual's mental representation of the technology and that these schemata are deeply colored by one's "gut reactions" to selected aspects of this mental image (e.g., dread, concern for the safety of future generations, potential for the catastrophe, etc.). Parallel findings were reported for the indicator of "acceptable" risk.

The evidence for perceptions of benefits is less clear, in part because the measurement of "perceived benefit" has proven to be a more difficult task than the psychometric measurement of perceived risk. Indeed, one of the major challenges facing researchers
Table I. 18 Risk Characteristics

\begin{tabular}{ll}
\hline \multicolumn{1}{c}{ Factors } & \multicolumn{1}{c}{ Risk characteristics } \\
\hline Factor 1: "Dread" & 1. Severity not controllable \\
& 2. Dread \\
3. Globally catastrophic & 4. Little preventive control \\
5. Certain to be fatal & 6. Risks and benefits inequitable \\
& 7. Catastrophic \\
& 8. Threatens future generations \\
& 9. Not easily reduced \\
& 10. Risks increasing \\
& 11. Involuntary \\
& 12. Affects me personally \\
& 13. Not observable \\
Factor 2: "Familiarity" & 14. Unknown to those exposed \\
& 15. Effects immediate \\
& 16. New (unfamiliar) \\
& 17. Unknown to science \\
& 18. Many people exposed \\
\hline
\end{tabular}

in this field of inquiry is the development of robust indicators for the measurement of perceived benefit. The difficulties in developing such indicators go well beyond the mechanics of designing and testing a variety of complementary measurement techniques; one is lacking, as well, a comprehensive theory of "perceived benefit."

One candidate for such a theory and associated measurement technique might be the "willingness to pay" criterion of welfare economics. In principle it should be possible to generate demand curves for certain products and services which indicate at each point along the curve one's willingness to pay for incremental additions of the good or service. This demand curve should also help to identify the consumer surplus (willingness to pay over the actual market price) which could be associated with the concept of net benefit. In practice such demand curves have proven quite difficult to generate, either because of the lack of appropriate market data or because of complex statistical problems related to the identification of a set of recursive equations.

Quite apart from the technical problems associated with the approach, however, one might legitimately question what it means at the individual level to ask about one's willingness to pay for automotive transportation or electrical energy, to take two examples, in a society that is structured around the availability and frequent use of both. Individuals may have relatively few options, particularly in the short run, 
for altering their consumption patterns with respect to technologies that are structurally embedded in the social fabric. If, as we suspect, one of the principal perceived benefits of technological systems such as these is their continued and uninterrupted availability, then questions probing the individual's willingness to pay for this availability will be strongly conditioned by an element of implied coercion.

This problem could be avoided in part through the development of interviewing techniques that assume implicitly a continuing flow of services; so that benefit, with respect to access and availability, remains roughly constant across technological options. The interviewing tasks would focus on the less tangible aspects of "perceived benefit" which might influence the individual's overall assessment of specific technological options. Then efforts at psychometric scaling would be directed toward individual judgments on issues like convenience, reliability, comfort, and design. The outcome of these efforts would be psychometric measurements of "perceived benefit" that would be descriptive, rather than normative, in nature.

We anticipate that psychometric research will demonstrate "perceived benefit" to be a multidimensional concept that is roughly complementary to that of "perceived risk." This is a very modest hypothesis. Benefit-cost analysts are fully aware that "benefits" are multifaceted; the trick of their profession is to find a means to map all of the separate elements into a single metric representing market value. There is, however, no single metric within psychological research that could withstand such heroic manipulations. Thus, one might anticipate research and debate concerning both the number and the composition of the dimensions that explicate "perceived benefit." Results reported by Slovic and his associates indicate that perceptions of risk and benefits are inversely correlated. Consequently, the perception of benefits may be affected in a fashion that is comparable, though inversely structured, to the perception of risks. We hypothesize that a balanced set of risk/benefit characteristics (i.e., a balanced schedule of positive and negative attributes) could lead to parallel conclusions concerning the factors that affect these complementary, though inversely correlated, perceptions.

Otway and Fishbein have conducted a number of small pilot studies of attitudes toward nuclear power in Austria. ${ }^{(18,19)}$ Their focus was primarily methodological: To develop methods for measuring differential perceptions of risks and benefits of nuclear power among individuals who held contrasting viewpoints on these issues. The theoretical model they adopted was that of Fishbein ${ }^{(20,21)}$ which seeks to link an individual's attitudes toward an object, a nuclear power plant in this instance, to the individual's belief structure, subjective evaluation of "truth" probabilities, intentions, and, ultimately, behaviors. ${ }^{(18)}$ Owing to the preliminary nature of these studies, the results are somewhat difficult to interpret. Nonetheless, Otway and Fishbein were able to obtain a factor structure using elicitation methods that are roughly comparable to those of Slovic and his associates. Furthermore, the schedule of attributes employed in these studies incorporated numerous positive characteristics in addition to the risk dimensions suggested by Lowrance: The positive attributes were associated with perceptions of benefit, especially among those subjects who were classified as being favorable to nuclear power. Finally, the belief structures evidenced by the "pro" and "antinuclear" subjects revealed sharp contrasts in their perceptual frameworks, emphasizing once again the importance of individual heuristics.

Green and Brown ${ }^{(22-25)}$ have studied perceptions of risk and safety in the United Kingdom using small samples of students and lay persons. Though their primary focus has been on perceptions of risk from fires, their methodology parallels in many respects that of Slovic and his associates. As was reported for Slovic's experiments, the findings of Green and Brown suggest the perceptions of risk and safety are strongly conditioned by the qualitative attributes associated with technologies and with risky activities. Green and Brown argue that these mental images constitute expectations, or "conjectures" about possible future occurences, and that the individual, as an "intuitive scientist," evaluates potential risk in accordance with these conjectures. This argument closely parallels recent discussions in cognitive psychology.

Vlek and Stallen ${ }^{(26)}$ have recently completed a major study of perceptions of risk among the residents of the metropolitan area surrounding Rotterdam, Netherlands. Unfortunately, the results of this study are not yet available for distribution in English. Personal communications with the principal investigators, however, indicate that this research project extended several techniques developed by Slovic and his collagues and that many of the preliminary research results corroborate those reported by Slovic. In particular, it appears that perceptions of risk from technologies and industrial facilities were influenced 
heavily by a wide range of qualitative characteristics that their subjects associated with these installations. Through the use of multidimensional scaling techniques ${ }^{(27-29)}$ Vlek and Stallen were able to develop cognitive maps of these perceptions in a format similar to the factor analyses reported by Slovic and Fischhoff. These cognitive maps indicate the primary dimensions along which risk is evaluated, the placement of various technologies within the perceptual space defined by these dimensions, and the relative acceptability of the risks involved. An additional aspect of this research was the use of Q-sort techniques as a means of revealing preferences among risky technologies and the extent to which subjects were willing to consider trade-offs between the risks and benefits associated with the technologies under consideration. This approach permits researchers to study not only the factors that affect perceptions of risk, but also the cognitive process of choice in the face of risk and uncertainty.

\subsection{Discussion}

On the basis of the studies that have been summarized above, it is possible to draw several conclusions concerning the most profitable avenues for further research on the question of perceived risk:

(1) Perceptions of risk among the lay population are poorly calibrated when compared with objective, statistical data. The relevant studies indicate that subjects rely upon individual heuristics when evaluating potential risk, and that these heuristics tend to systematically bias perceptions of risk. We conclude, therefore, that further research on this question should be guided by recent theoretical and methodological developments in cognitive psychology that stress schemata and information processing.

(2) Despite their lack of technical calibration, individual perceptions of risk can be analyzed successfully by recourse to psychometric techniques that allow subjects to characterize risky technologies and activities according to sets of qualitative dimensions such as those proposed by Lowrance and others. The number and composition of these "risk dimensions" varied slightly from one study to the next. These variations could result from any of three sources of instability: (a) differences in testing instruments, (b) differences in samples of subjects; or (c) fluctua- tions in attitudes over time. This latter observation leads to the suggestion that future research might seek to establish a standardized instrument that is administered to representative samples of some identifiable population at several points in time. This approach would allow one to identify both the source and the extent of any apparent fluctuations in risk perceptions.

(3) Perceptions of benefits have been studied more recently and somewhat less successfully than perceptions of risk. On the basis of available evidence, however, there is reason to believe that perceived benefits could be studied in a manner that is analogous to that which has proved successful for the study of perceived risk. Extrapolating from the work done by Otway and Fishbein and by Vlek and Stallen, we speculate that it will be possible to identify a limited set of perceived benefit dimensions that are based on responses to questions of a qualitative and comparative nature. Furthermore, we would expect that many of the methodological issues to be confronted in this research will be similar in nature to those that have been tackled in recent studies of perceived quality of life. ${ }^{(4,30)}$ The experience gained in mapping the dimensions of perceived life quality may prove quite useful in mapping the dimensions of perceived benefit from technologies.

(4) Through the use of multidimensional scaling techniques, it should be possible to develop cognitive maps which summarize the most salient dimensions along which perceived risk and benefit are evaluated. These analytic techniques would permit not only the identification of the most salient evaluative dimensions, but additionally could be used to cluster technologies and activities according to the similarity of their risk/benefit profiles and to identify subgroups of individuals who hold contrasting viewpoints on these issues.

(5) The bulk of research in this field has focused on perceptions of risk and the factors that comprise such perceptions. Questions of choice and consequent behavior have been touched upon only in passing. Having explicated some of the factors that comprise perceptions of risk, the researchers in this field might now seek to explore the extent to which these and other factors, such as those representing perceived benefit, explain preferences and choice behavior. For example, 
by incorporating sorting techniques as part of the data collection methodology it would be possible to obtain indications of individual preferences among activities that incorporate risky technologies. These preference structures could be analyzed in light of both the characteristics of the individual and the attributional profiles that the individual has assigned to a set of risky technologies. Analyses of this type, which fall within the tradition of standard econometric research, would reveal the factors that affect choice among risky alternatives as well as the decision weights that are assigned to each of these factors. Results of these analyses would indicate the potential for trade-offs among attributes and, in the absence of a single metric for risk and benefit, suggest the relative importance of the several factors in the actual choice process. Whereas research on the dimensions of perceived risk (and benefit) are valuable in their own right, we sense that the policy relevance of these findings will be more quickly grasped when they are cast within a framework of choice and behavioral response. In line with the recent work of Vlek and Stallen, we would argue for a shift in emphasis toward a more decision-theoretic framework that would focus research on the choice among activities that were characterized, in part, by risky consequences.

\section{PUBLIC PERCEPTIONS OF RISK AND THE THRESHOLD OF ACCEPTABLE RISK}

A crucial distinction in the study of perceptions of risk is that between (a) the levels of risk that the individual is willing to accept for himself in the course of his daily activities and (b) the levels of risk that the collectivity is willing to accept (tacitly or explicitly) as one of the several costs associated with the generation of a public benefit. We feel that the former question can be addressed from the theoretical perspective that we have outlined in the preceding section and about which we will have more to say in the next section. The latter question, concerning the "social acceptance" of risk, is more complex.

Arrow's paradox aside, one might speculate that within an idealized "democratic" culture, topical questions, such as the determination of socially acceptable levels of risk, could be resolved through the (weighted) aggregation of individual preferences.
This is not the case, as both the experiences of frustrated political leaders and the literature of political science and sociology would readily verify. The determination of an "optimal" resolution to a social controversy can be frustrated, or even precluded, by such factors as:

(1) the biases present in existing social and political traditions;

(2) the fallibility of institutionalized procedures for social decision-making;

(3) a substantial investment in an existing "suboptimal" course of action;

(4) a strategic balancing of preferences across disparate spheres of activity;

(5) an imprecise understanding of the secondary impacts of specific decisions or courses of action;

(6) the lack of information regarding feasible alternatives;

(7) the pressure exerted by highly motivated and resourceful minorities.

A full investigation of these and related topics would require the concerted efforts of specialists in such disciplines as political science, sociology, economics, engineering, and law, and is beyond the scope of the present discussion.

In keeping with the social science orientation of the present discussion, we would like to review briefly a selection of literature that highlights some of the difficulties of determining a threshold of "socially acceptable" risk. Indeed, in light of the complexities that characterize any social decision-making process, and the theoretical and empirical ferment that characterize research in this field, we are doubtful that any threshold of "socially acceptable" risk can be derived analytically at the present time.

In the section that follows we will note briefly the formal, analytic methods that have been proposed for the determination of socially acceptable levels of risk. We will discuss as well the reasons why these methods have proved problematic in practice. Analytically derived standards for public safety are particularly vulnerable in the face of conflicting or competing value systems, as a brief review of the nuclear power and fluoridation controversies demonstrates. ${ }^{(31,32)}$ This suggests that the development of socially acceptable standards for risk will depend, in part, on a better understanding of these conflicting value systems, with special emphasis on the potential for social mobilization in defense of mutually exclusive intergroup values. We point out, however, that 
research along these lines will be difficult and will likely require new forms of interdisciplinary cooperation.

\subsection{Analytic Approaches to Risk Analysis}

A variety of analytic approaches have been applied to the analysis of risk from technologies with the objective of determining a socially optimal tradeoff between risks and benefits. These methodologies are generically grouped under such headings as riskbenefit analysis, decision analysis, cost-effectiveness analysis, and the like. The characteristic common to all of them is a formal structure that strives to make explicit the assumptions, value judgments, and criteria that shape and guide the decision process. Thus, they seek first to quantify all relevant aspects of a decision involving technical risk and then calculate the optimal trade-off between (a) the benefits of the risky technology, and (b) the probability or magnitude of the potential adverse consequences of that technology.

The stated advantage of these approaches is that they provide an explicit structure for addressing problems that can be exceedingly complex. The technologies in question may be imperfectly understood, either in terms of their long-term operating characteristics or their secondary impacts. As regards the potential social impacts, these may entail difficult value trade-offs, or suggest disturbing equity impacts. Furthermore, there may be uncertain institutional consequences either in terms of further reinforcing selected institutional structures or creating serious new challenges to already embattled institutions. Problems of this magnitude may be intractable by any intuitive decision-making process; thus formal methodologies can serve, in the minimum, to structure the question at hand and, thereby, highlight the associated unknowns and imponderables.

It is generally recognized, however, that these procedures are not perfect. For the most part they have been developed within institutional frameworks in which a formal decision-making responsibility could be identified, objectives stated, and potential outcomes enumerated. With respect to decisionmaking in the public sector, however, these conditions are rarely met. Decision-making authority may be quite dispersed, the broader objectives of social institutions are frequently a source of controversy in themselves, and the outcomes, at least in the long term, are rarely known with any precision. Thus, despite their potential advantages, analytic procedures for risk analysis in the public sector may be inapplicable; especially as one passes from the level of decision-making within a single institution to that of policy-making for the entire nation. Policy recommendations which stem from these approaches are likely to be challenged seriously in the political arena if they threaten the value systems or belief structures of politically active and resourceful minorities.

A major and unresolved question in this field of research is that of determining threshold levels of acceptable risk: Is there a socially acceptable level of risk against which system designers might gauge their efforts? Economists argue that social preference functions should be derived from historical market records of choice and behavior. ${ }^{(33)}$ Starr has extrapolated from this concept in his frequently cited attempt to determine the social acceptance of risk from technologies. ${ }^{(34)}$ His stated concern in performing this analysis was to focus the issue of public safety on a "tangible, quantitative, engineering design objective" for use, for example, in the design of safety features for nuclear electric power plants. ${ }^{(34)}$ The use of historical data, some of which is of questionable accuracy, leaves open the question of whether one can distinguish "what is "best' for society from what is 'traditionally' acceptable." After generating timeseries data for a collection of indicators of social risks and social benefits, Starr fit a set of curves suggesting, among other things, a substantial difference in the willingness of people to accept "voluntary" risks, such as cigarette smoking, as compared to "involuntary" risks, such as those associated with the generation of electric power.

Starr's methodology rests on two assumptions, which he notes at the outset of his investigation: first, "that historical national accident records are adequate for revealing consistent patterns of fatalities in the public use of technology;" and second that "historically revealed social preferences and costs are sufficiently enduring to permit their use for predictive purposes."(34)

The results of Starr's analysis, as well as the methodology with which they were derived, have been critically reviewed by Otway and Cohen ${ }^{(35)}$ and Fischhoff et. al. ${ }^{(16)}$ In a reanalysis of Starr's time series data Otway and Cohen were unable to replicate Starr's reported results, and concluded by noting 
that:

the results of this method appear to be excessively sensitive to the assumptions made and the handling of data; the present existence of any such mathematical risk-benefit relationships, based upon this approach, would seem unlikely... There is clearly some relationship between the benefits perceived to be derived from an activity and the perceived cost of participation. The relationships are, however, not simple mathematical ones, but complicated and strongly influenced by socio-psychological mechanisms which are as yet not well understood. ${ }^{(35)}$

Despite the serious epistemological and methodological difficulties associated with attempts to quantify a socially acceptable threshold for technological risk, the incentive to do so remains high. Alternative methodologies have been proposed [e.g., see Rowe in ref. (36), Okrent and Whipple (37)], and the debate within the professional community is continuing.

\subsection{Public Controversies over Technological Risk}

The advantages of formal approaches to the analysis of technological risk would appear to be greatest in those instances where the consequences of a potential accident are quite high. Paradoxically, when risks assume a "catastrophic" potential, the value of a formal analysis may decline sharply. By their nature, risk-benefit analyses are obliged to incorporate and make explicit certain assumptions, value trade-offs, and decision criteria; the explication of these assumptions is considered to be a merit of the procedure by some. ${ }^{(38)}$ The complexity of a major risk-benefit analysis, however, leaves it subject to legitimate scientific scrutiny and rebuttal. On points where the technical judgment is unanimous, the general public is likely to defer to the expert view. The development of a scientific controversy over the merits of the report, however, may serve to stimulate public controversy and political mobilization.

Organized groups that are seeking to represent a particular viewpoint in the political arena, tend to use scientific evidence selectively and in a manner that supports their position. ${ }^{(39,40)}$ Consequently, pressure groups with an identifiable stake in an impending policy decision may legitimately challenge the findings of a formal risk analysis by questioning key assumptions and by presenting conflicting evidence. On the one hand, the formal analysis may be characterized as an intentionally biased and, therefore, political document; on the other hand, it may be dismissed as a fundamentally flawed analysis. Case studies of such controversies ${ }^{(39-41)}$ suggest that by challenging the scientific legitimacy of an expert report, the opponents of a technology not only may negate the impact of certain expert advice, but may also stimulate public debate and political action. Thus, a complex and potentially controversial riskbenefit analysis may backfire as a policy tool:

\footnotetext{
...We generally assume that informed scientific advice is valuable to political policy-makers. However, in the context of a controversial political issue, and when the relevant technical analysis is ambiguous, then the value of scientific advice becomes questionable. A technical controversy sometimes creates confusion rather than clarity and it is possible that the dispute itself may become so divisive and widespread that scientific advice becomes more of a cost than a benefit to the policy-maker and society. ${ }^{(41)}$
}

When such disputes occur at the community level, and the protagonists are willing to engage in a direct confrontation of their opinions, one might attempt to reconcile the differences through a dialogue procedure. This would entail the engagement of facts with values and, in particular, scientific judgment with decision-makers' values. Vickers ${ }^{(42)}$ regards "facts as relevant only in relation to some judgment of value and judgments of value as operative only in relation to some confrontation of fact... Judgments dísclose... a set of readiness to distinguish some aspects of the situation rather than others and to classify these in this way rather than that." Social decision theorists ${ }^{(43)}$ have developed face-to-face procedures for groups to confront and deal with these problems at the community level. Three steps are involved:

(1) Objectively measured variables and externalization of the scientific judgments implied by these data.

(2) Externalization of the social value judgmentsmeaning the importance of outcome dimensions.

(3) Integration of the two forms of judgments in cluding the salience of "facts" to "values" and vice versa.

The first two steps might be developed independently, and often are, but their integration requires a dialogue for the discovery of omitted facts and unforseen values. Apart from its role in policy decision-making the model suggests aspects of personal decision-making that will be discussed in more detail 
in the next section. The model is most readily applied within the framework of a community-level dispute. Controversies surrounding the social acceptability of risk, however, frequently assume a national scope as aspects of national policies are called into question. The direct dialogue approach may be less applicable in these circumstances.

The establishment of "socially acceptable" thresholds for technological risk will require, at a minimum, the acquiescence of large segments of the population. Consequently, there is an incentive for all parties involved in a technological controversy to appeal directly to the lay persons who comprise the vast majority of the general public. The lay public constitutes a latent political resource that may be mobilized in support of, or in opposition to, a controversial risky technology. An indirect effect of such public information campaigns could be the establishment of (inconsistent) thresholds for the public acceptance of risk in reference to specific, controversial technologies rather than the design of technological systems in light of a publicly accepted threshold for risk. The associated concern among technologists is that analytic consistency in the determination of standards for risk may fall prey to the political process. $^{(38)}$

\subsection{Value Conflicts and Social Movement Organizations}

Recent history demonstrates that within most western democracies, public debates over the risks associated with technologies have become more frequent and occasionally quite divisive. ${ }^{(44,45)}$ Given that most members of the public are unaware of the technicalities that are involved, either by lack of appropriate training or through lack of interest, the most effective strategy for the protagonists in these debates is to appeal directly to the personal or social values that can be rallied in defense of their position. Thus, nuclear power has been defended under the banner of continued economic growth, energy independence, national prestige, and general "progress;" it has been opposed with reference to public health and safety, the concentration of economic and political authority, and the threat of terrorism..$^{(19,44-47)} \mathrm{At}$ least three issues are involved here. The first is the social distribution of potentially conflicting value systems and belief structures which might serve to segment the public in a manner that favors one or the other of the protagonists. The second issue concerns the strategies and tactics of those organized groups that are working actively to mobilize political support, both in the public domain or in the more restricted realm of the political and economic "elites." Finally, if one is interested either in an empirical description of these processes or in the possibility of predicting their impacts, then one should review the suitability of the predominant social science methodologies.

Empirical studies of social behavior, such as the Survey Research Center's studies of attitudes toward violence ${ }^{(5,6)}$ have demonstrated that the link between an individual's conception of social issues and the same individual's predisposition toward participation in social action is mediated by such factors as: a general willingness to participate in group activities, a positive identification with potential group leaders, a belief in the efficacy of social action, and one's physical proximity to locations of social and political ferment. Therefore, within a large group of individuals, each of whom shares an approximately comparable perspective on the desirability of social change, many will not act on their beliefs, some will act alone, some will get caught up in a social action movement, and a very small fraction will initiate collective behavior. Despite the low percentage of social activists and group leaders, there remains a pool of individuals that constitutes a latent source of support for social action if the means for mobilizing this resource can be identified.

Schattschneider ${ }^{(48)}$ and others have discussed the potential for mobilizing this latent source through deliberate efforts to redefine the questions that constitute current political debate and thereby restructure the pending social-political agenda. Bachrach and Baratz ${ }^{(49)}$ have emphasized the crucial role that values and belief structures play in this process. With specific references to health and safety legislation, Walker ${ }^{(50)}$ has discussed and documented the growth of agenda-setting forces in the U.S. Senate that were stimulated in part by the perception of widespread popular support for new regulatory efforts in these fields. The apparent spread of technological controversies in western nations has been attributed in part to a general decline in public confidence in science and technology. ${ }^{(51-53)}$ Nelkin and Fallows argue that a major factor stimulating the nuclear power debate is public concern for "the concentration of power in impersonal expertise-dominated bureaucracies." (54) With respect to environmental 
controversies, Ingelhart ${ }^{(55,56)}$ has focused on the emergence of "post-materialist" values in western societies. As these references suggest, the political sensitivity of previous "non-issues" may increase substantially through the emergence or deliberate exploitation of new value systems. Skillful disputants in a public controversy will argue not only the merits of the program under scrutiny, but also the relevance of the value systems and belief structures by which that program will be adjudged. Thus, divergences in value orientations among members of the general public represent potential lines of cleavage which can be exploited to shape a new political agenda.

A properly designed survey instrument can study directly the social distribution of potentially conflicting value systems and, through an analysis of demographic characteristics, evaluate the economic and political resources represented by these potentially political factions. Latent support for specific positions in a public controversy can be linked with individual values and beliefs, and the strengths of these associations can be analyzed. Survey data can indicate the spreading recognition of, and potential support for, organized social movement groups with specific stakes in a public controversy. These data can incorporate as well measures of belief systems and personality characteristics that predict political participation $^{(57)}$ and the justification of potentially disruptive political and social behaviors. ${ }^{(5,6)}$ Thus, we feel that the analytic scope of survey research has expanded considerably in recent years. By its nature, however, survey research is addressed to the attitudes and attributes of individuals. When considering the potential for political mobilization, the survey approach has acknowledged limits.

A survey approach is useful in identifying subgroups within the population that share particular value systems; we might refer to these subgroups as "factions." Moe ${ }^{(58)}$ refers to factions as collections of individuals interested in common problems or motivated by common purposes. Although in part factions define the social climate, their structural diffuseness and incapacity for endurance may render them less important in the political process than organized groups. From this perspective one might challenge the pluralist notions of common interest factions and emphasize the need for coercion, separate incentives, or collective goods in the achievement of organizational form and influence. ${ }^{(59)}$

Students of social movements, such as McCarthy and Zald, ${ }^{(60)} \mathrm{Moe}^{(58)}$ or Gamson and Modigliani (personal communication), argue that a like-minded faction may constitute a potential resource for social action, but does not by itself constitute a social movement. In their work they emphasize the professionalization of social movements and the means for mobilizing resources. Zald emphasized financial resources apart from membership strength and is working on the ideological and social location of the pro- and antinuclear groups within the context of general social movement theory. Gamson and Modigliani stress the role of the media in generalizing political symbols and metaphors that serve to frame and justify a position. They propose three types of engagement with social issues: self-interest, group identification, and social benefit ideology. Moe emphasizes economic model and the politics of organizational formation and maintenance, but recognizes as well departures from the economic ideal. While economic self-interest plays a major explanatory role in describing the behaviors of interest groups, he feels there are good reasons for investigating the behavioral implications of other, more diffuse value structures. Walker (work in progress) is analyzing public interest groups from the perspective of their links with social legislation, their associations with public bureaucracies, and their sources of funds. Access to government decision-making channels is a key focus of his research.

Since relatively few individuals belong to any particular set of organizations, a cross-sectional survey is not well suited to the study of organized, socially active groups. Survey data can be usefully complemented, however, by a parallel analysis of the organized social movement groups that are seeking to influence the pending political agenda. Research on the organizational strategies and mobilization tactics of social movement groups is being pursued by a number of sociologists who are using the public controversy over energy policies as their topical focus. To cite one example with which we are familiar, Zald, Gamson, and Modigliani are presently operationalizing their approaches to the study of social movements (and counter-movements) by focusing on the organizations and groups involved in the nuclear power controversy. They have interviewed the leadership of most of the pro- and antinuclear groups and are currently surveying their active memberships through attendance at conferences and public rallies. They are studying the structure of these organizations as well as their funding sources and sponsorship. Through secondary analyses of newspapers and journals, as 
well as through direct interviews with organization cadres, they are reviewing the alliances between social movement groups and their common mobilization strategies.

Work of this type, as well as that of other political scientists and sociologists not referenced here, would significantly enhance the interpretation of survey data concerning the public's perception of, and reactions to, technological risks. Research on the strategies and objectives of social movement groups concerned with risk issues could highlight the topical focus of their public information campaigns as well as the value systems and belief structures they were designed to exploit. Survey data, particularly that collected at multiple points in time, could indicate the extent to which these "messages" had been recognized and adopted by factions within the general public. To the best of our knowledge, however, there has been no recent attempt to combine survey work with sociological case studies in a concerted effort to analyze the implied brokerage of public opinion. This approach may lead to valuable new insights involving the cross-fertilization of theory and methodology in both areas of research. Such an attempt would certainly breach a currently accepted division of intellectual labor.

\subsection{Discussion}

As was mentioned at the opening of this section, the "social acceptability" of risk is affected by numerous social, political, and institutional factors, many of which fall outside the scope of the present discussion. A limited review of recent literature suggests, however, that the social processes affecting the acceptance of risk are multiple, complex and poorly understood. A variety of theoretical approaches and research methodologies are taking shape which conceivably could be used to investigate the processes that determine social standards for acceptable risk. At the present time, however, there is no body of social science data that could be used to establish specific thresholds of socially acceptable risk.

Formal, analytic approaches to the study of "socially acceptable" risks have a number of attractive characteristics that have been noted widely in the literature. First, they provide structure for decision problems that would have an otherwise bewildering complexity. Furthermore, they can make explicit the assumptions or value judgments that might be left unstated in a less rigorously structured analytic procedure. The analysis can have considerable heuristic value for those who participate in its development and for those who are capable of interpreting the results. The conclusions indicate courses of action that are in keeping with narrowly defined notions of economic efficiency and social optimality. For the most part, these methodologies are normative: they indicate what society "ought to do" in light of available data and a variety of assumptions.

The normative character of the formal, analytic approaches is, perhaps, their most telling weakness as instruments of policy analysis. At the present time, policy-makers are faced with numerous riskmanagement choices for which the relevant information is only partially in hand. Information is needed that would help policy-makers in the following areas:

(1) the establishment of priorities in the allocation of funds for risk management programs;

(2) the establishment of priorities in the determination of safety standards;

(3) the anticipation of demands for information from concerned public groups;

(4) the evaluation of the stability and credibility of expert and public opinion related to safety issues; and

(5) the forecasting of public reactions to safety standards and risk abatement guidelines.

Of these five policy-support activities, a formal riskbenefit analysis could contribute to the first two, but would be of little or no assistance in the latter three. In particular, a formal risk-benefit analysis would be of questionable value if it led to a conclusion that was strongly opposed by a broad segment of the public, or by a resourceful and active organization that was seeking to represent the public's interests.

In the event of negative public responses to proposed safety standards and risk abatement guidelines, it would be of interest to policy-makers to determine whether the rejection of the policy was due to:

(1) a misperception of the inherent risks;

(2) a misreading of the formal risk analysis on which the guidelines were based;

(3) a failure on the part of the formal analysis to consider important dimensions of the technological risks and benefits; or

(4) the inability of the analytic procedure to reflect the value systems and belief structures within which the risks and benefits are scrutinized. 
The psychometric research reviewed in the previous section highlights a tendency on the part of the general public to misperceive risks as they are formally defined. That same body of research indicates, however, that perceived risk is a multidimensional concept and that only one of those dimensions is approximated by a formal definition, such as the number of fatalities per annum or the risk of death per hour exposure. Even less is known about the possible dimensions of "perceived benefit." Thus, it is unlikely that the currently practiced analytic methodologies will effectively reflect such public concerns as "dread" and "catastrophic potential" or their as yet unidentified complements in the realm of perceived benefits. In order for policy-makers to better anticipate public reactions to technological risks, they will need access to more descriptive research of the type reviewed in the two preceding sections of this report.

One of the major, unresolved issues complicating research on the social acceptance of risk is that concerning the individual's decision to adopt and to actively support a specific position in a public debate. It is assumed that perceptions of risks and benefits weigh heavily in that decision process. A review of the nuclear power and fluoridation debates indicates, however, that a variety of other considerations may influence the decision process. Individuals may give differential weight to broader social options, such as the pursuit of economic growth, the centralization of political authority, or the importance of national prestige. These differentially weighted values may lead individuals to adopt conflicting viewpoints on specific social questions in spite of their agreement on the relevant technical information. In addition, an individual's predisposition toward acting on a personal conviction will be influenced by his/her personality characteristics as well as by specific contextual parameters. Finally, we must consider the (fallible?) cognitive processes by which all of this is assimilated and processed in the course of reaching a decision. This leads us to speculate on two closely related points: the possible "irrationality" of the general public in its decisions regarding risks; and the relative weights assigned to risks, benefits, and the other criteria in the overall decision process.

Numerous individual and social activities comport some element of risk, as has been emphasized recently by the publication of comparative risk tables. Unless the decisions to undertake or promote these activities, however, have been made specifically with respect to the risk involved, it would be inap- propriate to charge broad segments of the general public with "irrationality" for having personally condoned some activities (e.g., driving) while having rejected others (e.g., the construction of a nuclear electric power plant). Furthermore, "risk", however defined, may not be the primary factor influencing the individual's position in a public controversy. It would be inappropriate therefore to equate a social decision on a specific activity or technology with a decision on a socially acceptable level of risk. Considerations of "risk" legitimately may have been balanced against other factors in the decision process.

The latter comment leads directly to the second point mentioned above; namely, the relative weights assigned to specific components of a decision problem. The topic of decision-making under conditions of risk and uncertainty has been discussed extensively in the literature and the next section of our paper is devoted to a review of selected theoretical models.

\section{CHOICE AND DECISION-MAKING UNDER CONDITIONS OF RISK AND UNCERTAINTY}

The study of choice and decision-making under conditions of risk and uncertainty has become an important field of inquiry for researchers in many fields. The literature now includes studies undertaken not only in psychology and economics, but also in political science, medicine, geography, and the numerous interdisciplinary specialties focusing on aspects of planning and policy-making. Published articles have become so numerous that overviews and summaries of findings are appearing every three or four years. ${ }^{(8,61-68)}$ In this section we shall highlight some of the general conclusions and alternative approaches that appear to have a direct bearing on the individual reactions to perceived risk.

Expected utility theory ${ }^{(69,70)}$ has guided more than 30 years of research on decision-making under conditions of risk. Leading theorists have accepted it as a normative model for national behavior ${ }^{(71)}$ and have argued that reasonable people should strive to obey the axioms of the theory. ${ }^{(72)}$ Psychologists and other investigators, however, seeking to apply the logical precepts of the theory as a descriptive tool, have noted numerous and persistent anomalies. ${ }^{(14,73-78)}$ On the basis of evidence that is presently available one can argue that expected utility theory has purchased its formal elegance and norma- 
tive power through the adoption of a rigorously reductionistic perspective. In doing so, the theory has compromised its descriptive potential when addressing problems involving subjective estimates of probability. Tversky and Kahneman have commented that:

\begin{abstract}
The major contribution of this approach is that it provides a rigorous subjective interpretation of probability which is applicable to unique events and is imbedded in a general theory of rational decision... For judged probabilities to be considered adequate, or rational (however), internal consistency is not enough. The judgments must be compatible with the entire web of beliefs held by the individual... The rational judge... will attempt to make his probability judgments compatible with his knowledge about (1) the subject matter; (2) the laws of probability; and (3) his own heuristics and biases. ${ }^{(14)}$
\end{abstract}

Recently elaborated theories of choice have attempted to enhance their descriptive capabilities by incorporating features such as limits on human information processing, personal risk preference functions, and context effects. In doing so, the general notion of "satisficing" has come to dominate that of utility maximization in the recent literature.

\subsection{Prospect Theory}

Kahneman and Tversky's prospect theory exemplifies recent trends in this field. ${ }^{(78)}$ Their review of the experimental literature highlights several classes of choice problems for which the tenets of expected utility theory are violated consistently. The evidence suggests that people consistently overweight outcomes that can be considered as "certain" relative to those that are merely "probable". Whereas this "certainty effect" leads to risk aversion when the prospects are evaluated as gains, it leads to risk seeking when the prospects are evaluated as losses. Thus, a preference for a certain gain in the positive domain is replaced by a preference to avoid a certain loss in the negative domain. Furthermore, as a means of simplifying choice problems, subjects tend to focus their attention on aspects of the offered choices that serve to distinguish one from the other; common components are disregarded (the "isolation" effect). Thus, inconsistent choice patterns can be observed by merely altering the representation of the prospects. Finally, experiments suggest that subjects infer the value of a prospect with respect to the possible gains and losses it entails rather than in reference to their final assets. This observation stresses the importance of the subjective reference point that is used in the evaluation of possible gains and losses.

Prospect theory responds to these observations by incorporating two premises that deviate markedly from those of expected utility theory. First, "value is assigned to gains and losses rather than to final assets;" second, "probabilities are replaced by decision weights." (78) The actual choice process is assumed to involve two stages: an editing phase in which prospects are coded and simplified, and an evaluation phase in which the more highly valued prospect is chosen.

The editing phase recalls the earlier discussion of heuristics and biases: prospects are mentally coded as gains or losses with respect to a subjectively determined reference point, aspects common to the offered prospects are discarded or cancelled, dominated prospects are rejected, and the remaining prospects are simplified through rounding and the like. Kahneman and Tversky note that the representation of the "final edited prospects could, therefore, depend on the sequence of editing operations, which is likely to vary with the structure of the offered set and with the format of the display... Many anomalies of preference result from the editing process."(78)

During the evaluation phase, the edited prospect with the highest weighted value is selected. Kahneman and Tversky argue that "the carriers of value are changes in wealth or welfare... (thus)...value should be treated as a function in two arguments: the asset position that serves as reference point and the magnitude of change (positive or negative) from that reference point." (78) Value is weighted not by probabilities, however, but by decision weights that "measure the impact of events on the desirability of prospects (rather than) the perceived likelihood of these events."(78) Decision weights themselves exhibit a number of properties that violate standard assumptions. Of particular note is the finding that small probabilities tend to be overweighted and that decision weights rarely sum to unity.

We feel that prospect theory is relevant to a research program on risk perceptions for several reasons. By redefining value as a relative concept and by replacing subjective probability estimates with decision weights, prospect theory provides for a more robust descriptive account of choice under risk than does expected utility theory. Furthermore, though the theory has been demonstrated in reference to gambles involving monetary outcomes, the authors of the 
theory feel that it is "readily applicable to choices involving other attributes, e.g., quality of life or the number of lives that could be saved or lost as a consequence of a policy decision." (78) The hypothesized editing phase of the choice process remains something of a "black box." Current research on human information processing and schemata may suggest guidelines for prestructuring choice problems, thereby allowing for a post hoc interpretation of this phase of the choice process. In the event that one can devise choice problems for which the anticipated gains and losses can be unambiguously identified, it should be possible to generate empirical estimates for the relevant decision weights.

\subsection{Portfolio Theory: Personal Risk Preference}

Coombs has developed a theory of decisionmaking under conditions of risk in which the choice among uncertain options is conceptualized as a compromise between the maximization of expected value and the optimization of the level of risk. ${ }^{(77)}$ As such, the theory postulates the existence of a personal risk preference function that is single-peaked for fixed expected values. ${ }^{(79)}$

With expected value fixed, then a gamble reflects a conflict between greed and fear, and approach-avoidance conflict, and this condition means that for each individual there is an optimum level at which greed and fear are in unstable balance-at a lower level of risk, greed drives him on, and at a higher level of risk, fear holds him back-so preference falls off in either direction from the optimum value. ${ }^{(77)}$

Indeed, the nature of "risk" is left undefined by the formal theory. Coombs states that "the purpose of portfolio theory is to provide a basis for making inferences about the riskiness of gambles from preferential choices." (77)

We feel that the risk preference function of portfolio theory may provide an additional means by which to judge the levels of risk that are perceived to be associated with technologies. As was mentioned earlier, preference orderings among technologies can be analyzed on the basis of the attributes that are associated with them. For technologies that render comparable services (approximately equal expected values from the perspective of the subject), it may be possible to obtain an indicator of perceived "pure risk" by predicting the preference ordering on the basis of the schedule of principal attributes and then analyzing the residual. The success of this approach will depend, of course, on specifying a predictive model that incorporates the major, relevant attributes. In the event that risk preference is a stable trait across choice tasks, it may be possible to pursue this approach by developing a separate indicator of risk preference from an analysis of choice among gambles, entering this indicator into the predictive model, and then analyzing changes in the residual. We sense that Coombs' portfolio theory has significant empirical, as well as theoretical, interest for new research in this field.

\subsection{Elimination by Aspects and by Trees}

A third theory that would be highly relevant to an expanded program of research on risk perceptions is that of "elimination by aspects." (75) Strictly speaking, elimination by aspects (EBA) is not a model of risky choice in the fashion of portfolio theory or prospect theory; rather, it is a probabilistic theory of choice that views choice as a covert process of elimination. Within prospect theory, for example, the choice alternatives are characteristically represented as having a single aspect relevant to the choice task: gains or losses relative to a subjectively determined reference point. These gains or losses are then discounted by application of a decision weight, and the prospect with the highest weighted value is selected. In the EBA model, the objects of choice are represented by sets of aspects (e.g., color, size, cost, comfort, etc.) which both define the object within the choice problem and serve as the carriers of value. Thus, one might assume that the "rational" subject would sum across the value-weighted aspects that characterize each of the objects of choice and then choose that object with the highest total value. This is not the case, however. Instead, choice is assumed to proceed by an elimination process during which "an aspect is selected (with probability proportional to its weight), and all the alternatives that do not include the selected aspect are eliminated. The process continues until all alternatives but one are eliminated." (75) It should be noted at the outset that the model can be formulated as a dual in which aspects are interpreted as disadvantages. In this instance the selection of an aspect would lead to the elimination of all objects that contained the selected aspect.

One of the more interesting features on the EBA model is that it accounts for inconsistencies in choice 
behavior that stem from "context effects." A standard assumption in the theories of probabilistic choice has been that of "simple scalability;" i.e., "that the alternatives can be scaled so that each choice probability is expressible as a monotone function of the scale values of the respective alternative."(75) This assumption implies that if an individual is indifferent between two objects, $x$ and $y$, then he should choose them with equal probability regardless of the choice set within which they are contained. Experimental results have demonstrated the assumption to be false: choice probabilities can shift markedly depending upon the context in which the objects are presented.

Choice probabilities, therefore, reflect not only the utilities of the alternatives in question, but also the difficulty of comparing them. Thus, an extreme choice probability (i.e., close to 0 or 1) can result from either a large discrepancy in value or from an easy comparison... The comparability of the alternatives, however, cannot be captured by their scale values and hence simple scalability must be rejected. ${ }^{(75)}$
This feature underscores the potential effect of public information campaigns that seek to characterize an object, or a technology, according to a single aspect that can be arguably presented as having overriding importance to the process of choice.

Tversky has demonstrated this model using settheoretic notation. Acknowledging the limitations in generality which may result from an alternative representation of the model, we have considered the model within a matrix structure, as illustrated in Fig. 1. In their simplest form, the entries in the matrix $\left(m_{i j}\right)$ assume binary values $(1,0)$ to indicate whether or not an object of choice $\left(x_{i}\right)$ includes an aspect $\left(a_{j}\right)$. Each row in the matrix $\left(x_{i}^{\prime}\right)$ defines an "aspect profile" for an object of choice, thereby specifying the subset of aspects that identify a particular object within the choice problem; row $A^{\prime}$ delimits the subset of all possible aspects that are relevant to a particular choice problem. Similarly, each column in the matrix $\left(A_{j}^{\prime}\right)$ defines a set of alternatives; i.e., the subset of

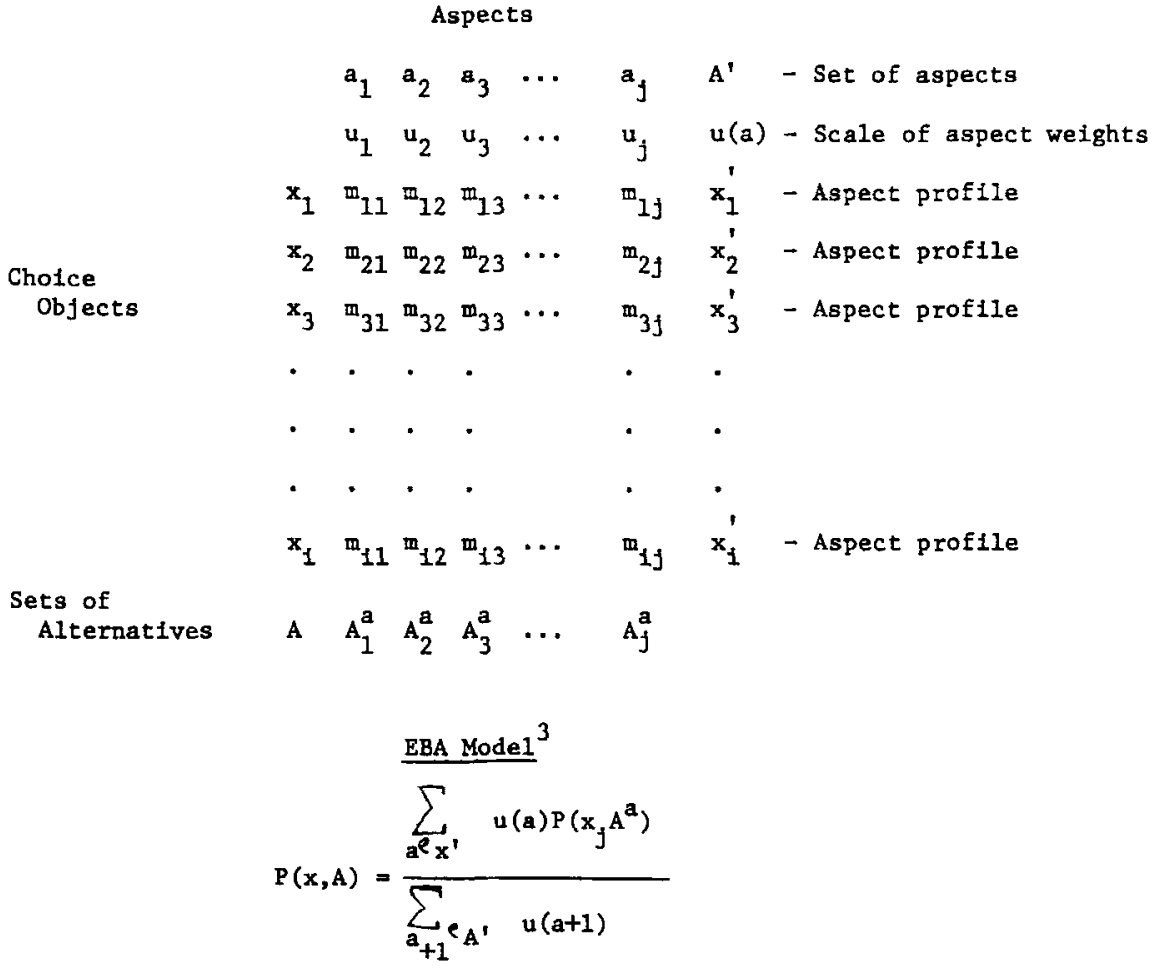

Fig. 1. Matrix Representation of EBA Choice Model. See Tversky(73) for a full exposition of the model. If the ordering of attributes can be prespecified, for example through a ranking of aspects, then the model becomes lexicographic. EBA Model: this recursive formula expresses the probability of choosing $x$ from the total choice set $A$ as a weighted sum of the probabilities of choosing $x$ from the proper subsets of $A$ (i.e., $A_{1}^{a}, A_{2}^{a}$, etc.). 
objects that have a particular aspect in common; column $A$ defines the set of objects that are under consideration in the choice problem. Finally, we define a scale " $u_{j}$ " which assigns to each aspect a positive value that reflects its utility to the decisionmaker and assume that aspects will be selected in an order that approximates the ranking of these scale values.

The choice process represented by the EBA model is highly general, though somewhat unwieldy. Tversky and Sattath ${ }^{(80)}$ have demonstrated that the covert process of elimination represented by EBA can be given a hierarchical structure if the objects under consideration are not disjoint with respect to aspects (see ref. 80: p. 546 and Appendix A). A hierarchical tree representation of the choice problem greatly simplifies the structure of the decision process and drastically reduces the number of parameters in the model. Furthermore, Tversky and Sattath demonstrate (ref. 80: Appendix B) that the preference tree "provides a versatile representation of choice that is compatible with both random-access and sequentialaccess strategies" (ref. $80:$ p. 548 ). If one were to employ this model in a program of research on the perceptions of technological risk, the objects of choice (activities involving the use or reliance upon a selection of technologies) would be evaluated with respect to a set of predetermined aspects, such as the schedules of positive and negative attributes discussed in Section 2. of this paper. We feel that the preference tree model would be applicable as a theoretical guide in the analysis of preferences among risky technologies.

Within the elimination by tree model (EBT), choice depends upon the order by which aspects are selected and the specification of the aspect profiles for the set of objects under consideration. As long as each object can be distinguished by a unique aspect, then a unique resolution to the problem might be assured. Consider, however, the possibility in which the last positively weighted aspect is selected, and yet several objects are represented in that set of alternatives $\left(A_{j}^{a}\right)$; the probability of selecting any one object in $\left(A_{j}^{a}\right)$ is, therefore, a function of the number of objects in the set. These probabilities may be more tightly specified, however, if we redefine the nature of the matrix elements $\left(m_{i j}\right)$ so that they may assume a range of values instead of a simple binary assignment. In many instances it is reasonable to consider the relationship between aspects and objects as being one of degrees rather than absolutes, and the $\left(m_{i j}\right)$ values might be assigned in a manner that reflects judgments on the degree to which an object incorporates or reflects a specified aspect. This approach should reduce the number of tied objects within any set of alternatives $\left(A_{j}^{a}\right)$ while adding additional detail to the aspect profiles $\left(x_{i}^{\prime}\right)$.

The approach suggested in the preceding paragraph is quite close to the elicitation procedures that have been employed successfully by Slovic et al., by Stallen and Vlek, and by Otway and Fishbein. Objects (i.e., technologies) and aspects (i.e., risk/benefit attributes) could be presented to respondents in the format of a modified semantic differential technique. By characterizing the technologies along the several dimensions of these evaluative scales, the respondents would generate aspect profiles in which the matrix elements $\left(m_{i j}\right)$ are permitted to assume a range of values. Aspect profiles $\left(x_{i}^{\prime}\right)$ composed of scaled matrix elements $\left(m_{i j}\right)$ would permit an empirical exploration of the EBT model.

\subsection{Discussion}

We feel that research on perceptions of technological risk should be expanded to incorporate directly the issue of preferences among activities that involve technological risk. Research on the choice among activities involving technological risk should seek to explore empirically the descriptive power of the several theoretical models discussed above. Prospect theory suggests the importance of decision weights, as compared with subjective probability estimates, in the choice among risky alternatives. We sense that this theory would be difficult to operationalize in the context of a questionnaire administered to broad segments of the public, but we would hope that the effort would be made, perhaps within the more restricted domain of an experimental project. Portfolio theory suggests that one should seek to develop indicators of personal risk preference, and we feel that this task is tractable even within the context of a cross-sectional survey.

Of the several theories reviewed above we feel that the EBA/EBT models would be most readily adapted to an expanded program of research on risk perceptions and their influences on preferences among risky activities. The generality of these models is very appealing and all of the elicitation procedures have been developed either within experimental settings or 
within survey contexts. The primary question concerning a direct operationalization of the EBT model is whether these separate, proven procedures could be employed in a complementary fashion. A schematic outline of one possible procedure is as follows.

First, subjects could be offered a set of objects (activities involving risky technologies) and asked to indicate their preferences through a sorting process. Additionally, these subjects would be asked to rankorder a set of pertinent aspects, such as those used by Slovic and others to develop risk and benefit profiles of technologies, thereby generating an indicator of $u$. Finally, using this same set of objects and aspects, the subjects would be asked to develop the matrix of elements $\left(m_{i j}\right)$ which both define the sets of alternatives with respect to aspects and specify the aspects' profiles. The strength of the model could be tested empirically by predicting the preference ordering of the objects on the basis of the rank-ordering of aspects and the aspect profiles. This possibility will be discussed further in the next section, which proposes a specific methodological approach to further research in this area.

Before moving on, however, we would like to make reference to an additional body of theory that we feel could have considerable impact on future research in this area. A systematic approach to components of cognition, particularly under conditions of impoverished information, is developing. In the current literature this approach is variously referred to as frames by Charnick, ${ }^{(81)}$ Minsky, ${ }^{(82)}$ and Goffman, ${ }^{(83)}$ or scripts by Schank and Abelson ${ }^{(84)}$ and Lehnert, ${ }^{(85)}$ or as schema by Becker, ${ }^{(86)}$ Bobrow and Norman, ${ }^{(15)}$ and Rumelhart and Ortony. ${ }^{(87)}$ Common to all these theories is the principle that information processing is bottom-up (evoked by incoming data and characteristics of stimuli) and also top-down as the person searches for information to fit into partially satisfied, higher-order schemata. Warren et. al. ${ }^{(88)}$ have developed an inference taxonomy for interpreting ambiguous events or event-chains involving logical, informational, and value inferences. A systematic hierarchy of perceptual levels has been proposed by Powers ${ }^{(89)}$ in which heuristics are a high level of interpretation. These are the rules that provoke action under uncertainty. Then there are existing models for event perception (equally suitable for hypothetical events) and for the behavior-perception interface. These models present some severe methodological problems, but we feel they offer a particularly insightful perspective on the question of choice and behavior under conditions of limited and uncertain information. They could be particularly useful, for example, in the development and interpretation of projective tests and open-ended probes concerning individual responses to hypothetical, though life-like, risky choices. Though the predictive power of these theories is, as yet, uncertain, their descriptive powers, as a unifying thread that runs throughout the several bodies of research touched upon in this paper is impressive.

\section{METHODOLOGICAL ISSUES}

Future research on perceptions of technological risks should seek to inform policy-making activities as well as to advance basic understanding of perceptions and their impacts on choice behaviors. Toward the attainment of these two broad objectives, at least four basic design parameters can be advanced.

First, we feel that future research should seek to explain the perceptions and attitudes of broad segments of the population; research performed on technically trained elites, or on samples drawn from college students, is not representative of the general population and may be misleading. Within the general population some individuals will be wellinformed, some individuals will be technically ignorant, and some will be indifferent with respect to the issues of technological risk. Given that many of the technological issues concerning risk are beyond the levels of training and interest of many individuals, it is of considerable interest to determine how they characterize risky technologies and activities, and how they formulate their potential behavioral responses. The clarity, structure, and cohesiveness of their perceptual spaces should be explored in detail, as well as the changes in perceptual patterns over time.

Secondly, in seeking to explore the structure and cohesiveness of these perceptual spaces, future research should emphasize the development of indicators of benefit perception. We have speculated on the possibility of developing indicators of benefit perception that would, roughly speaking, parallel those that have been developed for risk perception. Our previous research on the perceptions of life quality gives us some reason for optimism on this point. In any event, the question is open to empirical investigation. 
Thirdly, we feel that future research in this area should move explicitly toward an investigation of choice and behavior in the face of imperfect information concerning risky alternatives. We have stressed this issue at several points in our discussion. It has been assumed that perceptions of risk weigh very heavily in individual and collective decisions regarding support for technological developments; there is relatively little direct evidence on this question, however. An effort should be made to clarify the extent to which perceptions of risk affect choices among activities involving technologies, including the weight they are accorded in relation to other aspects, such as benefits.

Finally, as has been suggested above, we feel that future research should explore the stability and variability of perceptions of risks and benefits, of attitudes toward risky technologies, and of behavioral responses to risky choice problems. The longitudinal survey approach implicit in this formulation of a research agenda would be enhanced significantly through a direct collaboration with researchers working on case studies of social movement organizations.

\section{CONCLUSION}

In this literature review we have sought to draw linkages between several bodies of research in a manner that would highlight their complementarity and would facilitate the planning of new research programs on perceptions of technological risk. We have suggested a general approach for a renewed attack on the question of "perceived benefits" and have indicated how measures of perceived risks and benefits might be used to predict preferences among activities involving risky technologies. We have stressed the desirability of moving forward with research that would incorporate explicitly one or more of the recently elaborated theoretical models of choice under conditions of risk and uncertainty. We feel that this step is necessary not only to understand better the means by which individuals elect to support or oppose certain technological development, but also to make some purchase on the elusive question of "socially acceptable" risk. On this latter point, we are doubtful that the descriptive research which has been done up to now is sufficient to justify the establishment of any thresholds of "socially acceptable" risk. Research of a relevant nature is being performed, however, by a number of sociologists and political scientists.

Some of the positions we have adopted in this paper may be viewed as unorthodox in light of the research that is frequently cited in relation to the perceived risks of technologies. We hope, nonetheless, that they will stimulate new thinking in this relatively young research field.

\section{REFERENCES}

1. S. B. Withey, Reaction to Uncertain Threat, in Man and Society in Disaster, G. Baker and D. Chapman, eds. (New York, Basic Books, 1962)

2. S. B. Withey, Sequential Accommodations to Threat, in The Threat of Impending Disaster, G. H. Grosser, H. Weshsler, and M. Greenblatt, eds. (Cambridge, The M.I.T. Press, 1962).

3. S. B. Withey, The U.S. and the U.S.S.R., in Components of Defense Policy, Davis B. Bobrow, ed. (Chicago, Rand McNally, 1965).

4. F. M. Andrews and S. B. Withey, Social Indicators of WellBeing: Americans' Perceptions of Quality of Life (New York, Plenum Press, 1976).

5. M. D. Blumenthal, R. L. Kahn, F. M. Andrews, and K. B. Head, Justifying Violence: Attitudes of American Men (Ann Arbor, Michigan, Institute for Social Research, 1972).

6. M. D. Blumenthal, L. B. Chadiba, G. A. Cole, and T. E. Jayaratne, More About Justifying Violence: Methodological Studies of Attitudes and Behaviors (Ann Arbor, Michigan, Institute for Social Research, 1975).

7. P. Slovic, B. Fischhoff, and S. Lichtenstein. Facts and Fears: Understanding Perceived Risk, in Societal Risk Assessment, How Safe Is Safe Enough?, R. C. Schwing and W. A. Albers, eds. (Plenum Press, New York \& London, 1980) pp. 181-214.

8. S. Lichtenstein, B. Fischhoff, and L. D. Phillips. Calibration of Probabilities: The State of the Art, in H. Jungermann and G. de Zeeuw, eds., Decision Making and Change in Human Affairs (Dordrecht, Reidel, 1977).

9. A. H. Murphey and R. L. Winkler, Subjective probability forecasting experiments in meteorology: some preliminary results. Bulletin of the American Meteorological Society, 55, 1206-1216 (1974).

10. A. H. Murphey and R. L. Winkler, The use of credible intervals in temperature forecasting: some experimental results, in H. Jungermann and G. de Zeeuw, eds., Decision Making and Change in Human Affairs (Dordrecht, Holland, Reidel, 1977).

11. C. A. Stael von Holstein, An experiment in probabilistic weather forecasting. Journal of Applied Meteorology, 10, 635645 (1977)

12. P. Slovic and B. Fischhoff, Cognitive processes and societal risk taking, in J. S. Carrol and J. W. Payne, eds., Cognition and Social Behavior (Potomac, Md., Lawrence Erlbaum Associates, 1976). (Reprinted in H. Jungermann and G. de Zeeuw, eds., Decision Making and Change in Human Affairs, (Dordrecht, Reidel, 1977).

13. S. Lichtenstein, P. Slovic, B. Fischhoff, M. Layman, and B. Coombs, Judged frequency of lethal events. Journal of Experimental Psychology: Human Learning and Memory, 4, 551-578.

14. A. Tversky and D. A. Kahneman, Judgment under uncertainty, Science, 185, 1124-1131 (1974).

15. D. G. Bobrow and D. A. Norman, Some principles of memory schemata, in D. A. Bobrow and A. M. Collins, eds., 
Representation and Understanding: Studies in Cognitive Science (New York, Academic Press, 1975).

16. B. Fischhoff, P. Slovic, S. Lichtenstein, S. Read, and B. Coombs, How safe is safe enough? A psychometric study of attitudes toward technological risks and benefits. Policy Science, 9, 127-152 (1978).

17. W. Lowrance, Of Acceptable Risk: Science and the Determination of Safety, (Los Altos, California, Kaufmann, 1976).

18. H. J. Otway and M. Fishbein. The determinants of attitude formation: an application to nuclear power (RM-76-80). (Schloss Laxenburg, Austria, International Institute for Applied Systems Analysis, 1976).

19. H. J. Otway and M. Fishbein. Public attitudes and decision making (RM-77-54). (Schloss Laxenburg, Austria, International Institute for Applied Systems Analysis, 1977).

20. M. Fishbein, Readings in Attitude Theory and Measurement, (New York, Wiley, 1967).

21. M. Fishbein and I. Ajzen. Belief, Attitude, Intention and Behavior: An Introduction to Theory and Research (Reading, Ma, Addison-Wesley, 1975).

22. C. H. Green and R. A. Brown, Counting lives, Journal of Occupational Accidents (1978)

23. C. H. Green and R. A. Brown, Problems of valuing safety. (Borehamwood, Hertfordshire, U.K., Department of the Environment, Building Research Establishment, Note N 70/78, 1978).

24. C. H. Green and R. A. Brown, Metrics for societal safety (Borehamwood, Hertfordshire, U.K., Department of the Environment, Building Research Establishment, Note N 144/78, 1978).

25. C. H. Green and R. A. Brown, Perceived safety as an indifference function (Hertfordshire, U.K., Department of the Environment, Building Research Establishment, Note N $157 / 78,1978$ )

26. C. A. J. Vlek and R. J. M. Stallen, Persoonlijke beoordeling van risico's: Over risico's, voordeligheid en aamvaardbaarheid van individuele, maatschappelijke en industrièle activiteiten (University of Groningen, Institute for Experimental Psychology, 1979)

27. P. E. Shepard, A. K. Romney, and S. B. Nerlove, Multidimensional Scaling (Seminar Press, New York, 1972).

28. P. E. Green and V. R. Rao. Applied Multidimensional Scaling: A Comparison of Approaches and Algorithms (Dryden Press, Hinsdale, Illinois, 1972).

29. J. C. Lingoes et al. Geometric Representations of Relational Data (2nd edition, Ann Arbor, Michigan, Mathesis Press, 1979).

30. A. Campbell, P. E. Converse, and W. L. Rodgers, The Quality of American Life-Perceptions, Evaluations and Satisfactions (New York, Russell Sage Foundation, 1976).

31. D. Nelkin, Nuclear Power and Its Critics, (Ithaca, Cornell University Press, 1971).

32. A. Mazur, Disputes between experts, Minerva 11, 243-262 (1973).

33. E. Silberg, The Structure of Economics, (New York, McGrawHill, 1978).

34. C. Starr, Social benefit versus technological risk, Science, $\mathbf{1 6 5}$ 1232-1238 (1969).

35. H. J. Otway and J. J. Cohen, Revealed Preferences: Comments on the Starr Benefit-Risk Relationships (RM-75-5) (International Institute for Applied Systems Analysis, Schloss Laxenburg, Austria, 1975).

36. W. E. Rowe, An Anatomy of Risk (New York, Wiley, 1977)

37. D. Okrent and C. Whipple, An approach to societal risk acceptance criteria and risk management: Report No UCLA/Eng-7746 (Los Angeles, California, University of California, School of Engineering and Applied Science, 1977)

38. C. Starr and C. Whipple, Risks of risk decisions, Science, 208,
1114- $1119(1980)$

39. D. Nelkin, The political impact of technical expertise, Social Studies of Science, 5, 35-54 (1975)

40. D. Nelkin, Jetport, (New Brunswick, New Jersey, Transaction Books, 1975)

41. A. Mazur, Disputes between experts, Minerva, 11, 243-262 (1973).

42. Sir Geoffrey Vickers, The Art of Judgment: A Study of Policy Making, (New York, Basic Books, 1965)

43. Kenneth R. Hammond and L. Adelman, Science, values and human judgment, Science, 194, 389-396 (1976)

44. D. Nelkin, Technological Decisions and Democracy (Beverly Hills, Sage Publications, 1977)

45. D. Nelkin and M. Pollak, Political parties and the nuclear energy debate in France and Germany. Comparative Politics (January 1980)

46. A. J. Groth and H. G. Schutz, Voter attitudes on the 1976 California nuclear initiative, Environmental Quality Series No. 25 (University of California, Davis, Institute of Government Affairs, 1976).

47. B. D. Melber, S. M. Nealy, J. Hammersla, and W. L. Rankin Nuclear power and the public: analysis of collected survey research, (PNL-2340) (Seattle, Battelle Human Affairs Research Centers, 1977).

48. E. E. Schattschneider, The Semi-Scoereign people (New York, Holt, Rinehart and Winston, 1961)

49. P. Bachrach and M. S. Baratz, Two faces of power, American Political Science Review, 56, 947-952 (1962).

50. J. L. Walker, Setting the agenda in the U.S. Senate: a theory of problem selection, British Journal of Political Science, 7, 423-445 (1977).

51. Jurgen Schmandt, Crises and knowledge, Science, 174, 1-4 (1971).

52. Ina Spiegel-Rosing and Derek de Solla Price, The study of science, technology and society (SSTS): recent trends and future challenges, in Ina Spiegel-Rosing and Derek de Solla Price, eds., Science, Technology and Society (Beverly Hills, Califomia, Sage Publications, 1977).

53. Krishan Kumar, Prophecy and Progress. The Sociology of Industrial and Post-Industrial Society (London, Allen Lane, 1978).

54. D. Nelkin and R. Fallows, The evolution of the nuclear debate: The role of public participation, Ann. Rev. of Energy, 3, 275-312 (1978)

55. Ronald Inglehart, The Silent Revolution: Changing Values and Political Styles Among Western Publics (Princeton, N.J., Princeton University Press, 1977).

56. Ronald Inglehart, Value priorities and socioeconomic change, in Samuel H. Barnes and Max Kaase, eds., Political Action (Beverly Hills, California, Sage Publication, 1979).

57. S. Barnes et. al., Political action: mass population in 5 western democracies (Beverly Hills, California, Sage Publications, 1979).

58. Terry M. Moe, The Organization of Interest, (Chicago, Illinois, University of Chicago Press, 1980).

59. Maucur Olson, The Logic of Collective Action (Cambridge, Massachusetts, Harvard University Press, 1965).

60 J. D. McCarthy and M. N. Zald, The Trends of Social Movements in America: Professionalization and Resource Mobilization (Morristown, New Jersey, General Learning Press, 1973).

61. W. Edwards, Behavioral decision theory, Annual Review of Psychology, 12, 473-498 (1961).

62. P. Slovic, Assessment of risk-taking behavior, Psychology Bulletin, 61, 220-233 (1964).

63. G. M. Becker and C. G. McClintock, Value: behavioral decision theory, Annual Review of Psychology, 18, 239-286 (1967). 
64. W. Edwards and A. Tversky, Decision Making, Selected Readings (Middlesex, England, Penguin Books, 1967).

65. G. de Zeeuw, C. A. J. Vlek, and Wagenaar, eds., Subjective probability theory, experiments, applications, Acta Psychologica, 34, Nos. 2/3 (1970)

66. A. Rapoport and T. S. Wallsten, Individual decision behavior, Annual Review of Psychology, 23, 131-175 (1972).

67. D. Wendt, and C. A. J. Vlek, eds., Subjective Probability, Utility and Human Decision Making (Dordrecht, Reidel, 1974).

68. P. Slovic, B. Fishhoff, and S. Lichtenstein, Behavioral decision theory, Annual Review of Psychology, 28, 1-39 (1977).

69. J. Von Newman and O. Morgenstern, Theory of Games and Economic Behavior, (Princeton, Princeton University Press, 1944).

70. M. Friedman and L. J. Savage, The utility analysis of choices involving risks, Journal of Political Economy, 56, 279-304 (1948).

71. H. Raiffa, Decision Analysis: Introductory Lectures on Choices under Uncertainty (Reading, Massachusetts, Addison-Wesley, 1968).

72. R. L. Keeny and H. Raiffa, Decisions with Multiple Objectives: Preferences and Value Tradeoffs, (New York, Wiley, 1976).

73. M. Allais, Le comportement de l'homme rationnel devant le risque, critique des postulats et axiomes de l'ecole americaine, Econometrica, 21, 503-546 (1953).

74. C. H. Coombs and L. C. Huang, A portfolio theory of risk preference, (Michigan Mathematical Psychology Programme Report No. 68-5) (Ann Arbor, The University of Michigan, 1968).

75. A. Tversky, Elimination by aspects: a theory of choice, Psychological Review, 79, 281-299 (1972)

76. P. Slovic and A. Tversky, Who accepts savage's axioms? Behavioral Science, 19, 368-372 (1974).

77. C. H. Coombs, Portfolio theory and the measurement of risk, in M. F. Kaplan and S. Schwartz, eds., Human Judgment and Decision Processes (New York, Academic Press, 1975) pp. 64-83.
78. D. Kahneman and A. Tversky, Prospect theory: An analysis of decision under risk. Econometrica, 47, 263-291 (1979).

79. C. H. Coombs and G. Aurunin, Single-peaked functions and the theory of preference, Psychological Review, 84, 216-230 (1977).

80. A. Tversky and S. Sattath, Preferences trees, Psychological Review, 86, 542-573 (1979).

81. E. Charnick, Organization and inference in a frame-like system of common knowledge, in Proceedings of Theoretical Issues in Natural Language Processing: An Interdisciplinary Workshop (Cambridge, Massachusetts, Bolt, Beranek and Newman, 1975).

82. M. Minsky, A framework for representing knowledge, in P. H. Winston, ed. The Psychology of Computer Vision (New York, McGraw-Hill, 1975).

83. E. Goffman, Frame analysis, an Essay on the Organization of Experience, (Cambridge, MA, Harvard University Press, 1974).

84. R. Schank and R. Abelson, Scripts, Plans, Goals and Understanding, (Hillsdale, N.J., Lawrence Erlbaum Associates, 1977).

85. W. Lehneri, Human and computational question answering, Cognitive Science, 1, 47-73 (1977)

86. J. D. Becker, A model for the encoding of experiential information, in R. Schank and K. Colby, eds., Computer Models of Thought and Language (San Francisco, Freeman, 1973).

87. D. E. Rumelhart and A. Ortony, Representation of knowl edge, in R. C. Anderson, R. J. Spiro, and W. E. Montague, eds., Schooling and the Acquisition of Knowledge (Hillsdale, New Jersey, Lawrence Elrbaum Associates, 1977).

88. William H. Warren, D. W. Nicholas, and T. Trabasso, Event chains and inferences in understanding narratives, in Roy $O$. Freedle, ed., New Directions in Discourse Processing, Vol. II (Norwood, New Jersey, Ablex, 1979).

89. William T. Powers, Behavior: The Control of Perception (Chicago, Aldine, 1973). 